\title{
Influence of Meteorological Factors on the Potential Evapotranspiration in Yanhe River Basin, China
}

\author{
yu luo ${ }^{1}$, Peng $\mathrm{Gao}^{2}$, and Xingmin $\mathrm{Mu}^{3}$ \\ ${ }^{1}$ Institute of Soil and Water Conservation Chinese Academy of Sciences and Ministry of \\ Water Resources \\ ${ }^{2}$ Northwest A\&F University \\ ${ }^{3}$ Institute of Soil and Water Conservation
}

March 18, 2021

\begin{abstract}
Potential evapotranspiration $\left(E T_{0}\right)$ is an essential component of the hydrological cycle, and quantitative estimation of the influence of meteorological factors on $E T_{0}$ can provide a scientific basis for studying the impact mechanisms of climate change. In the present research, the Penman-Monteith method was used to calculate $E T_{0}$. The Mann-Kendall statistical test with the inverse distance weighting were used to analyze the spatiotemporal characteristics of the sensitivity coefficients and contribution rates of meteorological factors to $E T_{0}$ to identify the mechanisms underlying changing $E T_{0}$ rates. The results showed that the average $E T_{0}$ for the Yanhe River Basin, China from 1978-2017 was $935.92 \mathrm{~mm}$. Save for a single location (Ganquan), $E T_{0}$ increased over the study period. Generally, the sensitivity coefficients of air temperature (0.08), wind speed at $2 \mathrm{~m}(0.19)$, and solar radiation $(0.42)$ were positive, while that of relative humidity was negative $(-0.41)$, although significant spatiotemporal differences were observed. Increasing air temperature and solar radiation contributed $1.09 \%$ and $0.55 \%$ of the observed rising $E T_{0}$ rates, respectively; whereas decreasing wind speed contributed $-0.63 \%$, and relative humidity accounted for $-0.85 \%$. Therefore, it was concluded that the decrease of relative humidity did not cause the observed $E T_{0}$ increase in the basin. The predominant factor driving increasing $E T_{0}$ was rising air temperatures, but this too varied significantly by location and time (intra- and interannually). Decreasing wind speed at Ganquan Station decreased $E T_{0}$ by $-9.16 \%$, and was the primary factor underlying the observed, local "evaporation paradox." Generally, increases in $E T_{0}$ were driven by air temperature, wind speed and solar radiation, whereas decreases were derived from relative humidity.
\end{abstract}

\section{Hosted file}

Manuscript.pdf available at https://authorea.com/users/390959/articles/514153-influence-ofmeteorological-factors-on-the-potential-evapotranspiration-in-yanhe-river-basin-china 


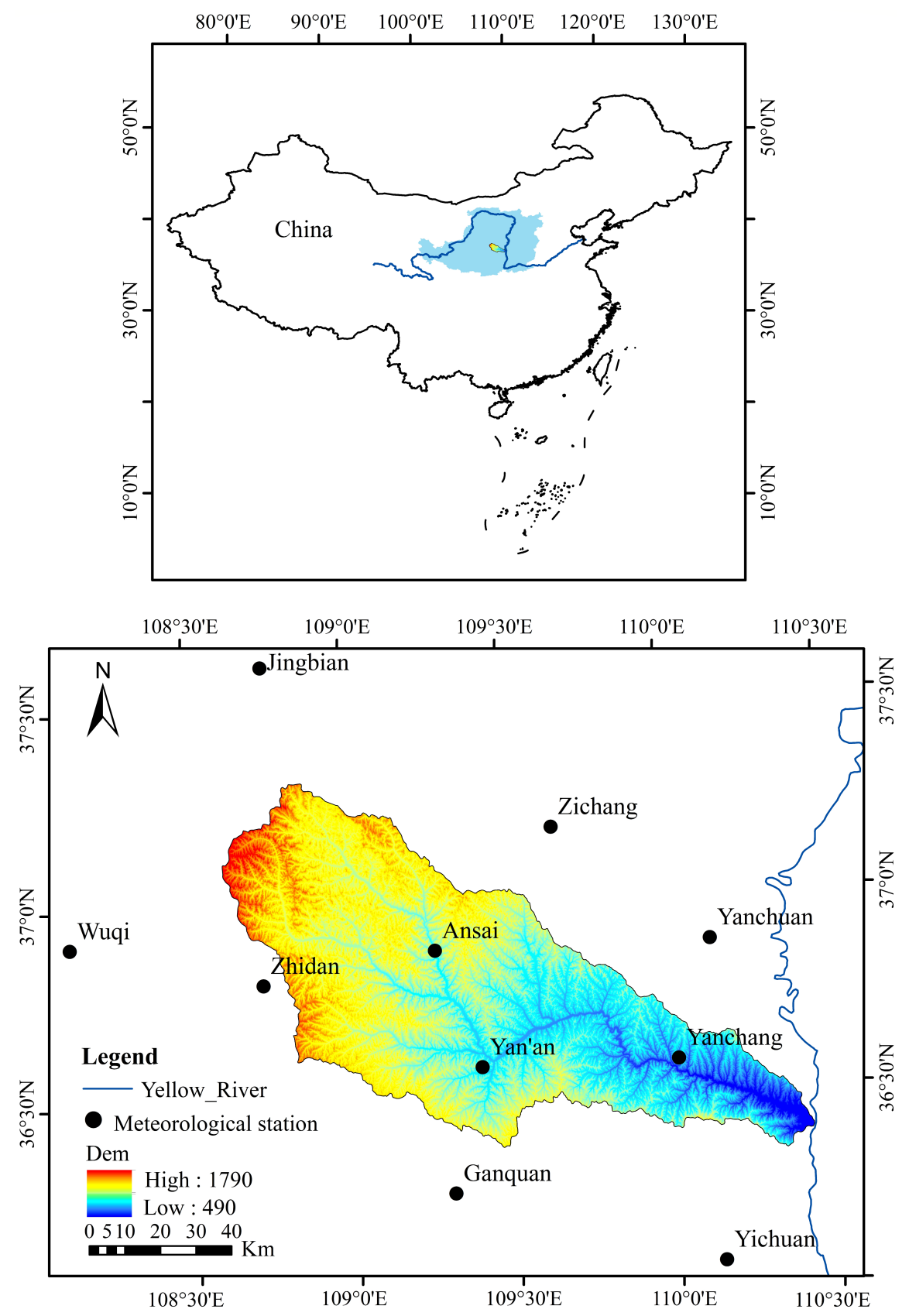



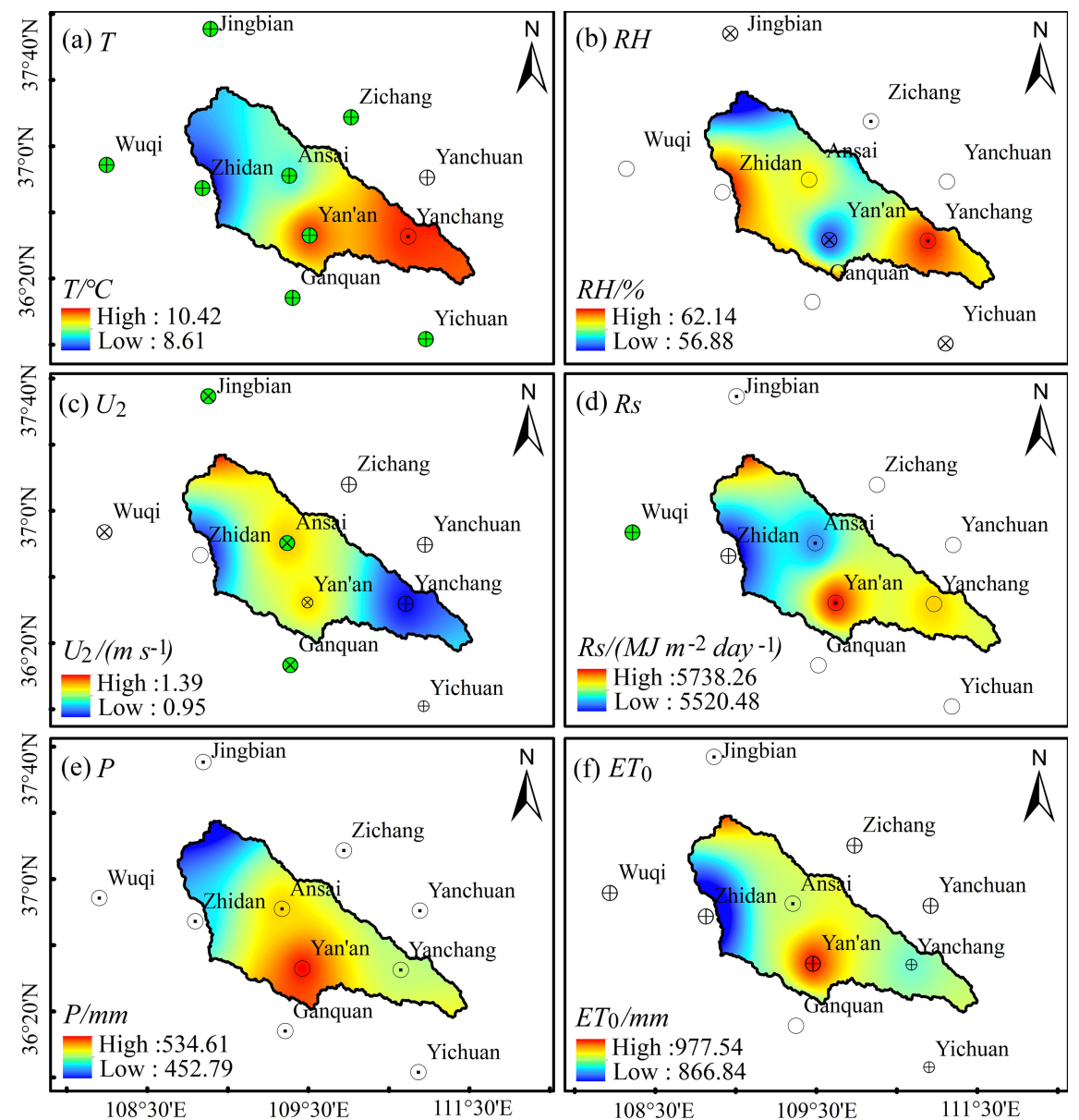

Legend

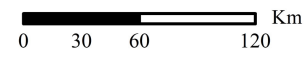

M-K statistics
$\odot 0 \sim 1.65$
$\oplus 1.65 \sim 1.96$
$\oplus 1.96 \sim 2.58$
(1) $>2.58$
- $-1.65 \sim 0$
$\otimes-1.65 \sim-1.96$
$\otimes-2.58 \sim-1.96$
$\otimes<-2.58$ 

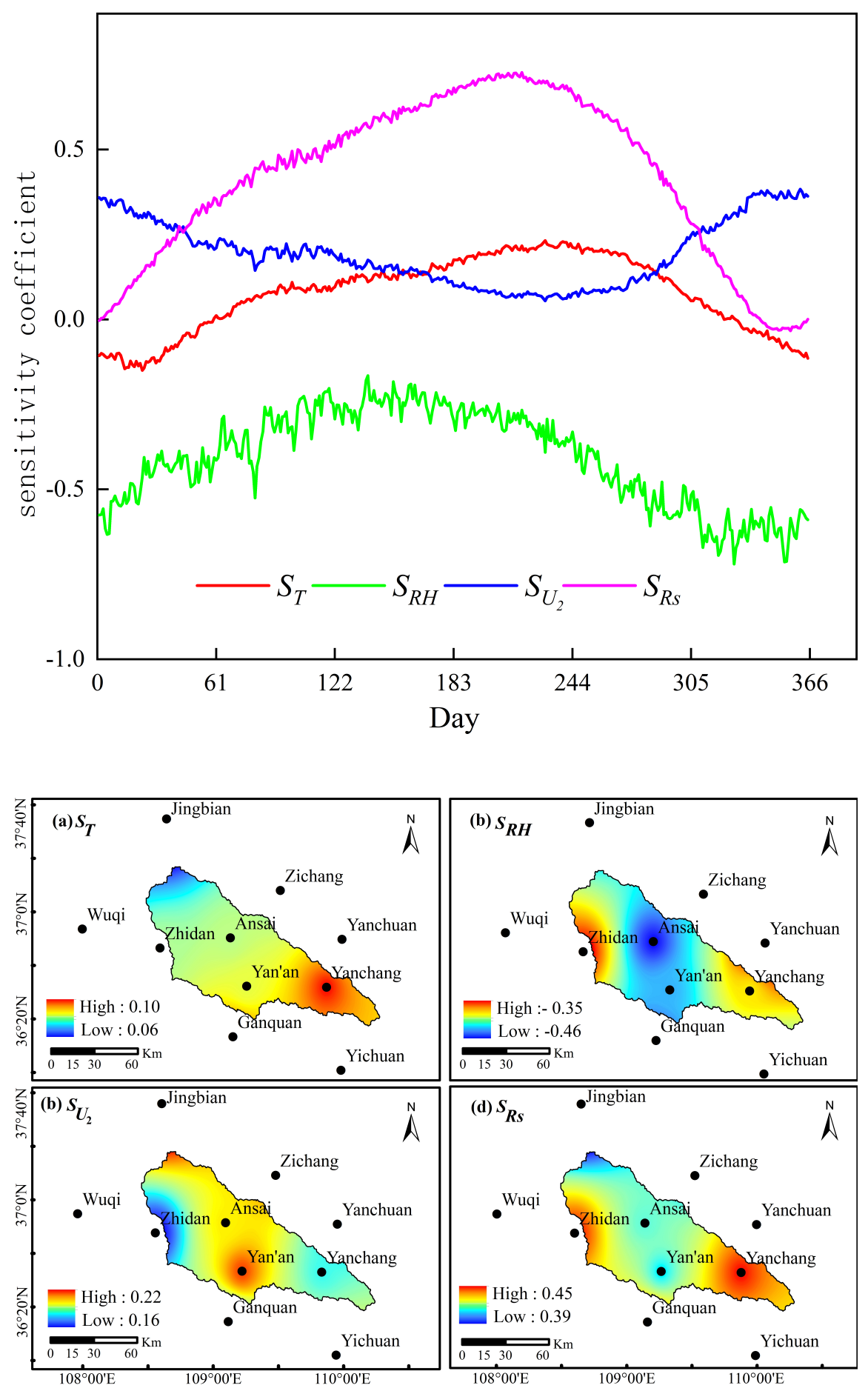


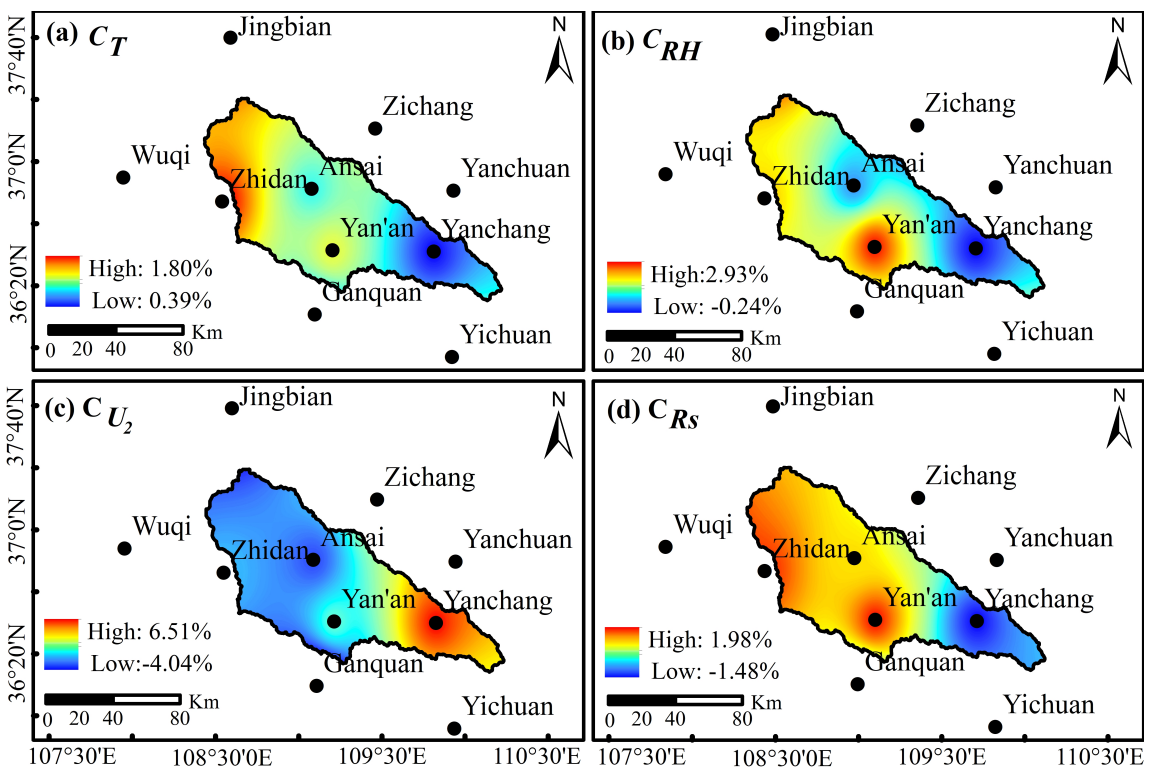

\section{Hosted file}

Tables.pdf available at https://authorea.com/users/390959/articles/514153-influence-ofmeteorological-factors-on-the-potential-evapotranspiration-in-yanhe-river-basin-china 